\title{
Penentuan Kadar Logam Timbal (Pb) pada Ikan Bandeng di Sekitar Pelabuhan Tanjung Mas
}

\author{
Determination of Lead (Pb) Metal Content in Milkfish near of Tanjung Mas Port \\ Feni Nilasari dan Yari Mukti Wibowo * \\ Fakultas Teknik Universitas Setia Budi Surakarta \\ *Corresponding author: yari_mukti@setiabudi.ac.id
}

\section{ABSTRAK}

Ikan bandeng merupakan ikan yang sangat populer di kalangan masyarakat umum karena harganya yang terjangkau dan kandungan gizi yang tinggi untuk pertumbuhan manusia. Tambak ikan bandeng yang berada pada sekitar kawasan industri yang dekat dengan Pelabuhan Tanjung Mas dicurigai bisa tercemar oleh logam berat seperti Timbal (Pb), yang dapat mengakibatkan dampak buruk bagi manusia apabila terakumulasi di dalam tubuh.

Metode analisis yang digunakan adalah Spektrofotometri Serapan Atom (SSA). SSA merupakan metode yang populer untuk analisis logam, karena di samping relatifsederhana, metode ini juga selektif dan sangat sensitif. Destruksi yang dilakukan pada sampel adalah destruksi kering dengan pemanasan pada suhu $550^{\circ} \mathrm{C}$. Sampel yang telah didestruksi lalu diukur menggunakan alat spektrofotometer serapan atom dengan menggunakan panjang gelombang $217 \mathrm{~nm}$ untuk $\mathrm{Pb}$. Absorbansi yang diperoleh kemudian dihitung menggunakan persamaan regresi linier yang didapatkan dari kurva baku untuk menentukan kadar logam $P b$.

Konsentrasi logam Pb dalam sampel ikan bandeng yang diambil dari tambak di sekitar Pelabuhan Tanjung Mas berada di bawah baku mutu yang ditetapkan oleh SNI No 7387 : 2009. Semakin jauh tempat pengambilan sampel dari kawasan industri, semakin kecil konsentrasi logam Pb yang ditemukan pada sampel ikan bandeng.

Kata kunci: bandeng, Pelabuhan Tanjung Mas, timbal, destruksi kering, spektrofotometri serapan atom.

\section{ABSTRACT}

Milkfish is a very popular fish because it is affordable and high nutrient content needed by the human body for growth. Milkfish ponds located around the industrial area that is near Tanjung Mas Port are suspected of being contaminated by heavy metals such as Lead (Pb). This metal can cause adverse effects on humans if it accumulates in the body.

Atomic Absorption Spectrophotometry (AAS) method is used in this analysis because it is relatively simple, selective and highly sensitive. The destruction carried out on the sample was dry destruction by heating at $550^{\circ} \mathrm{C}$. The samples that have been destructed are measured using atomic absorption spectrophotometer at $217 \mathrm{~nm}$ wavelength. The absorbance obtained is then calculated using the linear regression equation obtained from the standard curve to determine the Pb metal content.

The concentration of Pb metal in milkfish samples taken from ponds around Tanjung Mas Port is below the quality standard set by SNI No. 7387: 2009. Farther the sampling place from the industrial area, the smaller the Pb metal concentration found in the milkfish sample.

Keywords: milkfish, Tanjung Mas Port, lead, dry destruction, atomic absorption spectrophotometry

\section{PENDAHULUAN}

Ikan bandeng (Chanos chanos $s p$ ) merupakan salah satu jenis ikan air payau yang memiliki rasa yang khas dan telah dikenal di Indonesia bahkan di luar negeri. Ikan ini merupakan satu-satunya spesies yang masih ada dalam familia Chanidae. Hamper di seluruh provinsi di Indonesia dijumpai produsen ikan bandeng. Pembudidayaan ikan bandeng banyak ditemukan di Pulau Jawa, khususnya kota Semarang. Tambak ikan bandeng banyak ditemui di sekitar Pelabuhan Tanjung Mas. Di sekitar pelabuhan tersebut dijumpai pula beberapa industri besar. Oleh sebab itu dimungkinkan ikan bandeng yang dibudidaya di sekitar Pelabuhan Tanjung Mas dapat tercemar logam berat, khususnya logam timbal $(\mathrm{Pb})$. 
Logam timbal atau timah hitam $(\mathrm{Pb})$ merupakan logam berat yang terdapat secara alami di dalam kerak bumi dan tersebar ke alam dalam jumlah kecil melaui proses alami maupun buatan. Logam $\mathrm{Pb}$ yang terhirup atau tertelan oleh manusia, akan masuk pada aliran darah dan beredar ke seluruh tubuh, termasuk di dalam ginjal dan otak, dan disimpan di dalam tulang dan gigi. Manusia dapat terkontaminasi logam $\mathrm{Pb}$ melalui udara, debu, air, dan makanan. Masuknya logam $\mathrm{Pb}$ ke dalam tubuh manusia dapat melalui pernapasan dan pencernaan. Senyawa $\mathrm{Pb}$ yang termakan pada kosentrasi tinggi dapat mengakibatkan gejala keracunan $\mathrm{Pb}$ seperti rasa logam pada mulut, iritasi, muntah, sakit perut, gastrointestinal akut,dan diare

Metode analisis Spektrofotometri Serapan Atom (SSA) menjadi metode analisis yang paling sering digunakan untuk mengukur kadar logam dalam suatu sampel. Metode SSA ini dirasa sesuai untuk mengukur kadar logam $\mathrm{Pb}$ dalam sampel ikan bandeng di sekitar Tanjung Mas, karena metode ini relatif sederhana, selektif dan sensitive.

\section{METODE PENELITIAN}

\section{Bahan Penelitian}

Sampel ikan bandeng hasil tambak di sekitar Pelabuhan Tanjung Mas, Asam nitrat $\left(\mathrm{HNO}_{3}\right)$ pekat, Asam klorida $(\mathrm{HCl}) 5 \mathrm{~N}$, Larutan standar baku $\mathrm{Pb}\left(\mathrm{NO}_{3}\right)_{2} 1000 \mathrm{mg} / \mathrm{L}$ dari Merck, danAquabidest.

\section{Alat Penelitian}

Spektrofotometer Serapan Atom (SSA) Shimadzu AA-7000, lampu katoda berongga (Hollow Cathode Lamp) Timbal $(\mathrm{Pb})$, gelas beaker (100 mL dan $250 \mathrm{~mL}$ ), pipet volumetrik (1 mL, $5 \mathrm{~mL}, 10 \mathrm{~mL}, 20 \mathrm{~mL}$ dan $50 \mathrm{~mL}$ ), labu takar $(50 \mathrm{~mL}$ dan $100 \mathrm{~mL})$, cawan porselen, pemanas listrik (hot plate), corong gelas, batang pengaduk, oven, tanur, timbangan analitik, blender, desikator, kertas saring Whatmann No.41 bebas abu.

\section{Prosedur}

Pengambilan Sampel. Sampel ikan bandeng diambil dari kawasan tambak sekitar pelabuhan Tanjung Mas Semarang. Terdapat 5 (lima) stasiun tempat pengambilan sampel ikan bandeng. Sampel ikan bandeng tersebut diambil pada saat panen, yaitu berumur 2 bulan dan sampel ikan bandeng memiliki panjang yang hampir sama. Berikut adalah peta pengambilan sampel:

Preparasi Sampel. Sampel ikan bandeng dipisahkan antara daging dan tulangnya. Daging ikan bandeng dihaluskan menggunakan blender kemudian ditimbang sebanyak \pm 10 gram pada cawan porselen. Sebelumnya cawan tersebut telah dikeringkan menggunakan oven selama 1 jam pada suhu $105^{\circ} \mathrm{C}$. Lalu sampel diarangkan di atas hotplate. Kemudian sampel dimasukkan pada tanur selama 8 (delapan) jam

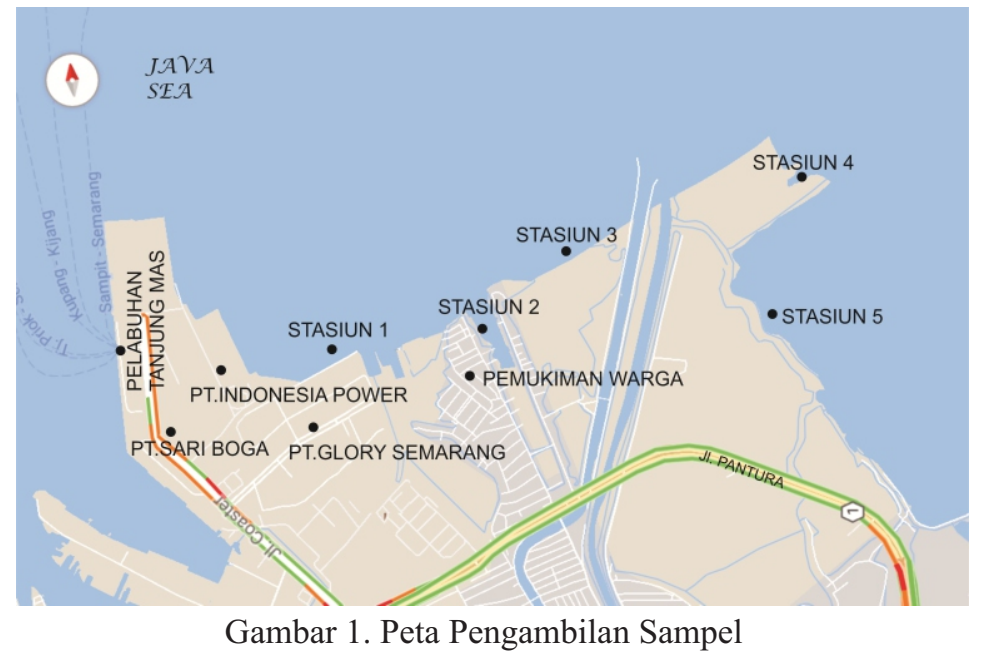


pada suhu $550^{\circ} \mathrm{C}$ atau sampai menjadi abu sempurna (abu berwarna putih). Tambahkan 2 $\mathrm{ml}$ aquabidest pada cawan porselen dan $2 \mathrm{~mL}$ $\mathrm{HNO}_{3}$ pekat, aduk hingga homogen. Masukkan pada labu takar $50 \mathrm{~mL}$ dan tambahkan aquabidest hingga tanda batas. Kocok hingga homogen, saring menggunakan kertas saring Whatmann No.41 bebas abu.

Pembuatan Larutan Standar. Sebanyak $1 \mathrm{~mL} ; 5 \mathrm{~mL} ; 10 \mathrm{~mL} ; 20 \mathrm{~mL}$; dan $50 \mathrm{~mL}$ larutan logam $\mathrm{Pb} 10 \mathrm{mg} / \mathrm{L}$ masing-masing dimasukkan dalam 5 buah labu takar $100 \mathrm{~mL}$, tambahkan 20 mL HCl $5 \mathrm{~N}$ lalu tambahkan aquabidest sampai garis tanda kemudian dihomogenkan sehingga diperoleh larutan standar logam $\mathrm{Pb} 0,1 \mathrm{mg} / \mathrm{L}$; 0,5 mg/L; 1,0 mg/L; 2,0 mg/L dan 5,0 mg/L.

Pembuatan Kurva Standar. Larutan seri standar Timbal 0,1; 0,5; 1,0;2,0 dan 5,0 mg/L masing-masing diukur absorbansinya dengan menggunakan Spektrofotometer Serapan Atom pada $\lambda=217 \mathrm{~nm}$. Membuat kurva hubungan antara absorbansi yang didapat dari hasil pengukuran larutan standar dengan konsentrasi larutan standar. Dari kurva tersebut didapatkan persamaan regresi linier dengan persamaan :

$$
\mathrm{y}=\mathrm{ax}+\mathrm{b}
$$

Dimana :

y adalah absorbansi larutan standar

a adalah kemiringan (slope)

$\mathrm{x}$ adalah konsentrasi larutan standar

$\mathrm{b}$ adalah titik potong pada sumbu y (intercept)

Menentukan konsentrasi sampel. Dengan memasukan absorbansi dari hasil pengukuran sampel, pada persamaan regresi kurva kalibrasi standar akan diperoleh konsentrasi sampel.

\section{Membandingkan Konsentrasi Sampel.}

Konsentrasi sampel yang didapat sebelum pengenceran diubah satuannya menjadi $\mathrm{mg} / \mathrm{kg}$ dengan cara:

Konsentrasi $\left(\frac{\mathrm{mg}}{\mathrm{kg}}\right)=\frac{\text { Konsentrasi sampel }(\mathrm{mg} / \mathrm{L}) \mathrm{x} \text { volume yang dibuat }(\mathrm{L})}{\text { massa sampel }(\mathrm{kg})}$ Kemudian dibandingkan dengan bawah baku mutu yang tercantum pada SNI No $7387: 2009$.

\section{HASIL DAN PEMBAHASAN}

Penelitian ini dilakukan dengan cara menghitung konsentrasi logam timbal $(\mathrm{Pb})$ yang terdapat pada ikan bandeng dengan menggunakan metode spektrofotometri serapan atom, dan membandingkannya dengan baku mutu yang telah ditetapkan pada SNI-19-28981992/Rev.1998. Bagian yang digunakan dalam penelitian ini adalah daging ikan bandeng, karena daging ikan bandeng tersebut yang sering dikonsumsi oleh manusia.

Untuk mengetahui kandungan logam $\mathrm{Pb}$ yang terdapat dalam sampel ikan bandeng, maka perlu dilakukan destruksi sampel terlebih dahulu agar logam $\mathrm{Pb}$ terpisah dari matriks sampel. Destruksi sampel dilakukan secara destruksi kering dengan pemanasan/pengeringan menggunakan tanur pada suhu $550{ }^{\circ} \mathrm{C}$ selama 8 (delapan) jam.

Untuk pembuatan kurva baku, dibuat satu seri larutan standar logam $\mathrm{Pb}$ dengan konsentrasi $0,1 \mathrm{mg} / \mathrm{L} ; 0,5 \mathrm{mg} / \mathrm{L} ; 1,0 \mathrm{mg} / \mathrm{L} ; 2,0 \mathrm{mg} / \mathrm{L}$ dan 5,0 mg/L. Masing-masing larutan standar tersebut diukur absorbansinya menggunakan Spektrofotometer Serapan Atom. Kemudian dibuat kurva baku hubungan absorbansi larutan standar logam $\mathrm{Pb}$ dengan konsentrasinya masing-masing. Didapatkan persamaan $\mathrm{y}=$ $0,1043 \mathrm{x}+0,0013$ dengan $\mathrm{R}^{2}=0,9998$. Grafik hubungan antara absorbansi dengan konsentrasi larutan standar logam $\mathrm{Pb}$ dapat dilihat pada Gambar 2.

Kurva baku yang diperoleh tersebut digunakan untuk menentukan konsentrasi logam $\mathrm{Pb}$ yang terdapat dalam sampel. Pengukuran konsentrasi logam $\mathrm{Pb}$ menggunakan alat spektrofotometer serapan atom dengan panjang gelombang $217 \mathrm{~nm}$. Konsentrasi tiap sampel kemudian dirata-rata dan dibandingkan dengan baku mutu yang telah ditetapkan oleh SNI 7387:2009. Analisis sampel dilakukan secara duplo. Konsentrasi logam $\mathrm{Pb}$ pada masing-masing stasiun tempat pengambilan sampel dapat dilihat pada Tabel 1 . 


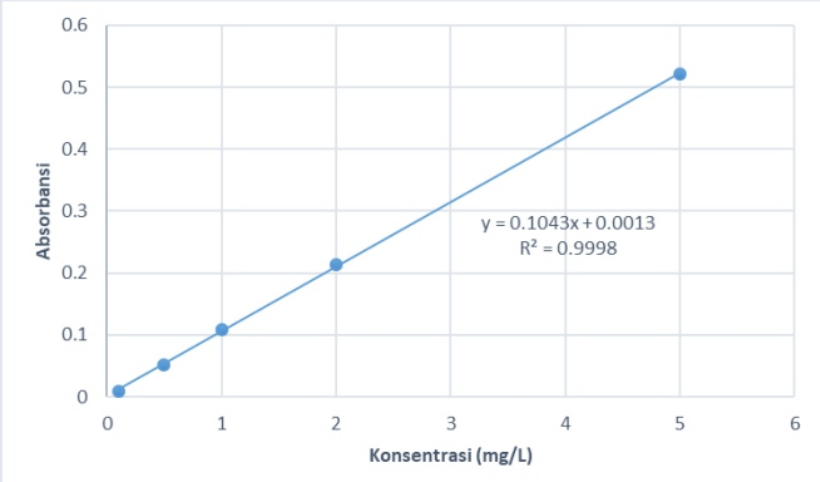

Gambar 2. Kurva Baku

Tabel 1. Konsentrasi Logam Pb

\begin{tabular}{ccc}
\hline Lokasi Sampel & $\begin{array}{c}\text { Rata-rata Konsentrasi Logam } \mathrm{Pb} \\
(\mathrm{mg} / \mathrm{L})\end{array}$ & $\begin{array}{c}\text { Rata-rata Konsentrasi Logam } \\
\mathrm{Pb}(\mathrm{mg} / \mathrm{Kg})\end{array}$ \\
\hline Stasiun 1 & 0,0346 & 0,1669 \\
Stasiun 2 & 0,0230 & 0,1142 \\
Stasiun 3 & 0,0125 & 0,0619 \\
Stasiun 4 & 0,0091 & 0,0280 \\
Stasiun 5 & 0,0034 & 0,0135 \\
\hline
\end{tabular}

Pada Tabel 1 dapat kita ketahui bahwa konsentrasi logam $\mathrm{Pb}$ pada masing-masing lokasi pengambilan sampel berada di bawah syarat baku mutu yang telah ditetapkan pada SNI No 7387 : 2009 yaitu sebesar $0,3 \mathrm{mg} / \mathrm{kg}$. Pada Tabel 1 tersebut kita juga bisa mengetahui bahwa dari Stasiun 1 ke Stasiun 5 harga konsentrasi logam $\mathrm{Pb}$ semakin kecil. Hal itu dapat disimpulkan bahwa semakin jauh lokasi pengambilan sampel dari kawasan industri, maka semakin kecil konsentrasi logam $\mathrm{Pb}$ pada sampel ikan bandeng. Walaupun konsentrasi logam $\mathrm{Pb}$ di kawasan tambak ikan bandeng sekitar Pelabuhan Tanjung Mas di bawah baku mutu yang ditetapkan oleh SNI No. 7387 : 2009, namun kawasan tambak tersebut tergolong bersifat tercemar, meskipun tingkat pencemarannya kecil. Oleh sebab itu perlu dilakukan upaya untuk meminimalisir sekecil mungkin adanya pencemaran logam $\mathrm{Pb}$ di kawasan tambak sekitar Pelabuhan Tanjung Mas.

\section{KESIMPULAN}

Konsentrasi logam $\mathrm{Pb}$ pada sampel ikan bandeng yang diambil dari tambak di sekitar Pelabuhan Tanjung Mas masih di bawah baku mutu yang ditetapkan oleh SNI No. $7387: 2009$. Semakin jauh lokasi pengambilan sampel dari kawasan industri, maka semakin kecil konsentrasi logam $\mathrm{Pb}$ pada sampel ikan bandeng.

\section{DAFTAR PUSTAKA}

Winarna, Rismawaty Sikanna dan Musafira. "Analisis Kandungan Timbal Pada Buah Apel (Pyrus Malus.L) Yang Dipajangkan di Pinggir Jalan kota Palu Menggunakan Metode Spektrofotometri Serapan Atom". Online Jurnal of Natural Science. Vol 4(1) :32-45. 2015.

Harmita. 2004. Buku Ajar Analisis Fisikokimia. UI Press. Jakarta.

Broekart J.A.C. 2002. "Analytical Atomic Spectrometry with Flames and Plasmas". Wiley-VCH: Weinheim. Jerman.

Badan Standardisasi Nasional. 1998. Cara Uji Cemaran Logam Berat dalam Makanan. SNI-19-2898-1992/Rev.1998.

Badan Standardisasi Nasional. 2011. Penentuan Kadar Logam Berat Timbal ( $\mathrm{Pb}$ ) dan Kadmium (Cd) pada Produk Perikanan. SNI 2354.5:2011.

Jeffery, G.H., Bassett, J., Mendham, J. dan Denney, R.C. 1989. Vogel's Textbook of Quantitative Chemical Analysis. $5^{\text {th }}$ Edition. Longman Scientifis \& Technical. London.

Harvey, David. 2000. Modern Analytical Chemistry. The McGraw-Hill Companies, Inc. Amerika.

Badan Standardisasi Nasional. 2009. Batas Maksimum Cemaran Logam Berat dalam Makanan. SNI 7387:2009. 